\title{
SALT-TOLERANT RHIZOBIA FOR ENHANCING COMMON BEAN (Phaseolus vulgaris L.) PRODUCTIVITY UNDER SALT STRESS
}

\author{
Ngo Nkot \\ Laurette $^{1+}$ \\ iD Youagang \\ Gougueu Harris \\ Stephane $^{2}$ \\ Semboung Lang \\ Firmin $^{3}$ \\ Timb Sara \\ Augustine Laurence ${ }^{4}$ \\ Dongmo Kenfack \\ Julio Lambert ${ }^{5}$ \\ Nwaga Dieudonne ${ }^{6}$
}

\author{
1,2,3,4.5 Department of Plant Biology, Faculty of Science, The University of \\ Douala, Douala, Cameroon. \\ 'Email:Inkot@yahoo.fr Tel: 699927716 \\ ${ }^{2}$ Email: hyouagang@yahoo.fr Tel: 691652231 \\ ${ }^{3}$ Email: langsemb@yahoo.fr Tel: 695260069 \\ "Email:timbsara@yahoo.fr.Tel:698255685 \\ ${ }^{5}$ Email: dongmojulio32@yahoo.fr Tel: 693488100 \\ ${ }^{6}$ Department of Microbiology, Faculty of Science, The University of Yaounde \\ I, Yaounde, Cameroon. \\ ${ }^{6}$ Email:_nwwaga@yahoo.fr Tel: 699931871

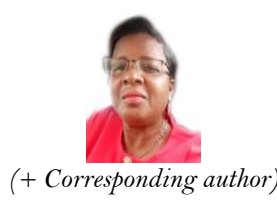 \\ (+ Corresponding author)
}

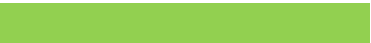

\section{Article History}

Received: 16 December 2021 Revised: 20 January 2022 Accepted: 4. February 2022 Published: 18 February 2022

\section{Keywords}

Salinity

Rhizobia

Common bean

Inoculation

Stress

Osmolytes.

\begin{abstract}
Salinity is one of the most important abiotic factors which are responsible for lower yields. To reduce its impact, conventional methods have been unable to solve the problem at all. In this context, developing sustainable methods which increase the productivity of saline soils without harming the environment is necessary. Some microorganisms such as rhizobia are tolerant to salt stress and can then grow in saline areas. Therefore, salt tolerant (ST) rhizobia are believed to reduce the impact of salinity on plant productivity. The aim of this study is to select the major salt-tolerant isolate of rhizobia that can alleviate salt stress in the common bean. Five salt-tolerant rhizobia were used for bean inoculation in greenhouse under salt stress $(0 \mathrm{mM}, 25 \mathrm{mM}$ and 50 $\mathrm{mM})$. A month after sowing, plants are harvested and analyzed for nodulation, growth and biochemical stress markers production. Collected data are analyzed statistically using SPSS 12.0. Results show that plant inoculation with ISRA352, PvNk8, PvMb1, PvNk7 reduces the effects of stress through the increase of growth, total pigments and osmolytes (proline and glycine betaine) contents compared to positive and negative controls. Plant inoculation with PvMb1 and ISRA352 led to low stress at $50 \mathrm{mM}$ of $\mathrm{NaCl}$. PvMb1, PvNk8 and PvNj5 are good inoculants for bean cultivation even in saltaffected soils. This research study contributes to allow the cultivation of bean in salty areas. On the other hand, the study comes up with a solution for remediation of saline soils yet to be enhanced.
\end{abstract}

Contribution/Originality: The study shows an alternative to the use of often polluting chemical fertilizers for the cultivation of common bean in saline conditions.

\section{INTRODUCTION}

The extent of land affected by salinity around the world is increasing and constitutes a major and serious hindrance to agricultural production especially in arid and semi-arid areas [1]. If judicious measures are not taken, salinization of farming soils will lead to the loss of up to $50 \%$ of soils in 2050 [2]. Common bean (Phaseolus vulgaris 
L.) which is a salt sensitive plant is nodulated by rhizobia in which certain are salt tolerant and able to alleviate salt stress [3-5]. Common bean inoculation with salt tolerant rhizobia could present a great solution for remediation of saline soils which are yet to be enhanced. The study aimed at evaluating the capacity of salt-tolerant rhizobia to alleviate salt stress on common bean.

\section{MATERIALS AND METHODS}

2.1. Common Bean Nodulating Bacteria

Five salt tolerant isolates (PvMb1, PvNj5, PvNj9, PvNk7 and PvNk8) of rhizobia nodulating common bean were used. The rhizobia are obtained from the collection of the Plant Biology and Physiology Laboratory of the University of Douala-Cameroon. A reference strain, ISRA 352 from LCM (Laboratoire Commun de Microbiologie) of Dakar-Senegal was also used for comparison.

2.2. Evaluation of the Effect of Inoculation by Salt Tolerant Rhizobia on Seedlings Growth, Symbiotic and Biochemical Parameters

The experiment was carried in pots inside a greenhouse. Sand was used as substrate after been washed several times with tap water and sterilized in an autoclave for $121^{\circ} \mathrm{C} / 1 \mathrm{~h}$. Plants were watered twice a week with the Jensen Nutrient solution $\left(\mathrm{K}_{2} \mathrm{HPO}_{4}\right.$ : O. $2 \mathrm{~g} ; \mathrm{MgSO}_{4}\left(7 \mathrm{H}_{2} \mathrm{O}\right)$ : 0. $2 \mathrm{~g} ; \mathrm{NaCl}: 0.2 \mathrm{~g} ; \mathrm{CaHPO}_{4}: 1 \mathrm{~g} ; \mathrm{FeCl}_{2}$ : 0. 14 g; $\mathrm{HBO}_{3}: 2.86$ $\mathrm{mg} ; \mathrm{MnSO}_{4}\left(6 \mathrm{H}_{2} \mathrm{O}\right): 2.03 \mathrm{mg} ; \mathrm{ZnSO}_{4}: 0.22 \mathrm{mg} ; \mathrm{CuSO}_{4}: 0.08 \mathrm{mg}$ and $\left.\mathrm{NaMbO}_{4}: 0.09 \mathrm{mg}\right)$. Three treatments with different concentrations of $\mathrm{NaCl}(\mathrm{O} \mathrm{mM}, 25 \mathrm{mM}$ and $50 \mathrm{mM})$. For each treatment, three sub-treatments were constituted:

- Inoculated plants with salt tolerant rhizobia.

- Non inoculated plants and watered with Jensen nutrient solution (NF control or negative control).

- Non inoculated plants and watered with Jensen nutrient solution supplemented with $1 \mathrm{~g} / \mathrm{L}$ of $\mathrm{KNO}_{3}\left(\mathrm{KNO}_{3}\right.$ control or positive control).

\subsubsection{Evaluation of Growth Parameters}

Plants total fresh and dry weight and also the number of leaves are taken 4 weeks after sowing, at the end of the experiment using an electronic scale (KERN). Seedlings fresh weights are taken immediately after harvesting, then dry in an oven at $70{ }^{\circ} \mathrm{C}$ until the weight is stable for the evaluation of the plant dry weight. Seedling total water content are evaluated. Seedling leaves number are also assessed.

\subsubsection{Assessment of Bean Symbiotic Parameters}

At the end of the experiment, the seedlings are harvested and the nodules collected from root system. The nodule number and size are registered to evaluate the nodular index.

\subsubsection{Evaluation of the Effect of Inoculation by Salt Tolerant Rhizobia on Biochemical Parameters \\ 2.2.3.1. Total Chlorophyll and Carotenoids Contents}

$1 \mathrm{~g}$ of fresh leaf, taken from the third and fourth leaf, is extracted by grinding in a mortar using $20 \mathrm{ml}$ of acetone. The optical density (OD) of the filtered extract is measured at 663, 645, and $440 \mathrm{~nm}$ to estimate chlorophyll a and b, and carotenoids respectively. The amount of pigment in each sample is calculated according to the following equations [6]:

Chlorophyll a= 12.25 (OD Chlb) - 2.79 (OD Chla)

Chlorophyll $\mathrm{b}=21.5$ (OD Chla $)-5.1$ (OD Chlb)

Chlorophyll a + chlorophyll $\mathrm{b}=7.15(\mathrm{OD}$ Chlb $)+18.71$ (OD Chla) 
Carotenoids $=$

\subsubsection{Physiological Stress Index}

Stress physiological index is obtained by dividing chlorophyll absorbance by total pheophytin absorbance [7]. For each sample, $230 \mathrm{mg}$ of fresh weight are taken and ground in a mortar in $5 \mathrm{~mL}$ of acetone (90\%) then put into $50 \mathrm{~mL}$ containing $15 \mathrm{~mL}$ of acetone $(90 \%)$ for $24 \mathrm{~h}$, in the dark at $5{ }^{\circ} \mathrm{C}$. The extract is centrifuged at $3000 \mathrm{rpm}$ for $10 \mathrm{~min}$ at $20^{\circ} \mathrm{C}$. The $\mathrm{OD}$ is registered at 665 and $750 \mathrm{~nm}$. The conversion of chlorophyll into pheophytin is realized by adding $10 \mu \mathrm{L}$ of concentrated $\mathrm{HCl}(37 \%)$ at $3 \mathrm{~mL}$ of extract. 2 minutes after, the OD is read one more time at 665 and $750 \mathrm{~nm}$. Physiological stress index (SI) is evaluated by the following formula:

$$
\mathrm{SI}=(\text { OD665 - OD750)/(OD665a - OD750a) }
$$

OD665a: acidified extract optical density at $665 \mathrm{~nm}$, OD750a: optical density of the extract at $750 \mathrm{~nm}$.

SI are interpreted through the Lopez and Carballeira [8] scale.

\subsubsection{Foliar Proline Content}

The proline content is determined using the method described by Troll and Lindsley [9]. Proline is extracted from leaves samples of $50 \mathrm{mg}$ fresh weight with $5 \mathrm{~mL}$ of methanol $(40 \%)$. Flasks are incubated at $85{ }^{\circ} \mathrm{C}$ for $1 \mathrm{~h}$, then $0.5 \mathrm{~mL}$ of the extract is mixed with $1 \mathrm{ml}$ of ninhydrin reagent the mixture is vortexed, then incubated $\left(90{ }^{\circ} \mathrm{C}\right.$ / $30 \mathrm{~min}$ ). After cooling, $3 \mathrm{~mL}$ of toluene are added to the mixture. The toluene fraction is read at $520 \mathrm{~nm}$.

\subsubsection{Foliar Glycine Betaine Content}

For the evaluation of betaine content in common bean, the method of Grieve and Grattan [10] is used. A 0. $5 \mathrm{~g}$ of leaves weight is grounded in $20 \mathrm{~mL}$ of distilled water and let for $48 \mathrm{~h}$ at $25{ }^{\circ} \mathrm{C}$. $0.5 \mathrm{~mL}$ of $\mathrm{H}_{2} \mathrm{SO}_{4}$ is add to the supernatant and let in ice for $1 \mathrm{~h}$. The OD of the mixture is read at $365 \mathrm{~nm}$.

\subsection{Statistical Analysis}

Collected data were subjected to analysis of variance (ANOVA) using SPSS 12.0 and means were separated by the Duncan test at $5 \%$ of probability level. All the graphs were realized using GraphPad Prism 5.0.

\section{RESULTS}

\subsection{Effect of Inoculation with Rhizobia on Common Bean Growth}

Figure 1 shows the effect of salinity on the number of leaves of inoculated plants. The increase in salt concentration of the medium causes a drop in the number of leaves for all treatments. Inoculation with salt-tolerant rhizobia significantly increased the number of leaves compared to the negative control but not significantly to the positive one.

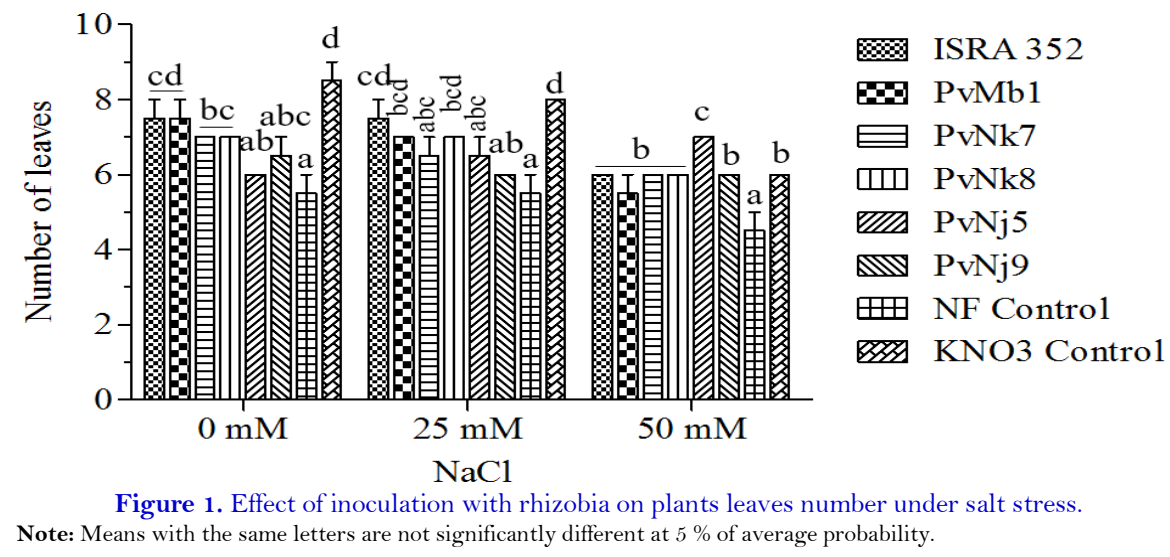


Salt stress caused a significant decrease in the fresh biomass of all plants. The lowest values were obtained in the negative control at all concentrations of $\mathrm{NaCl}$ Figure 2. Inoculation with rhizobia improved plant total fresh weight but not significantly compared to the nitrogen control.

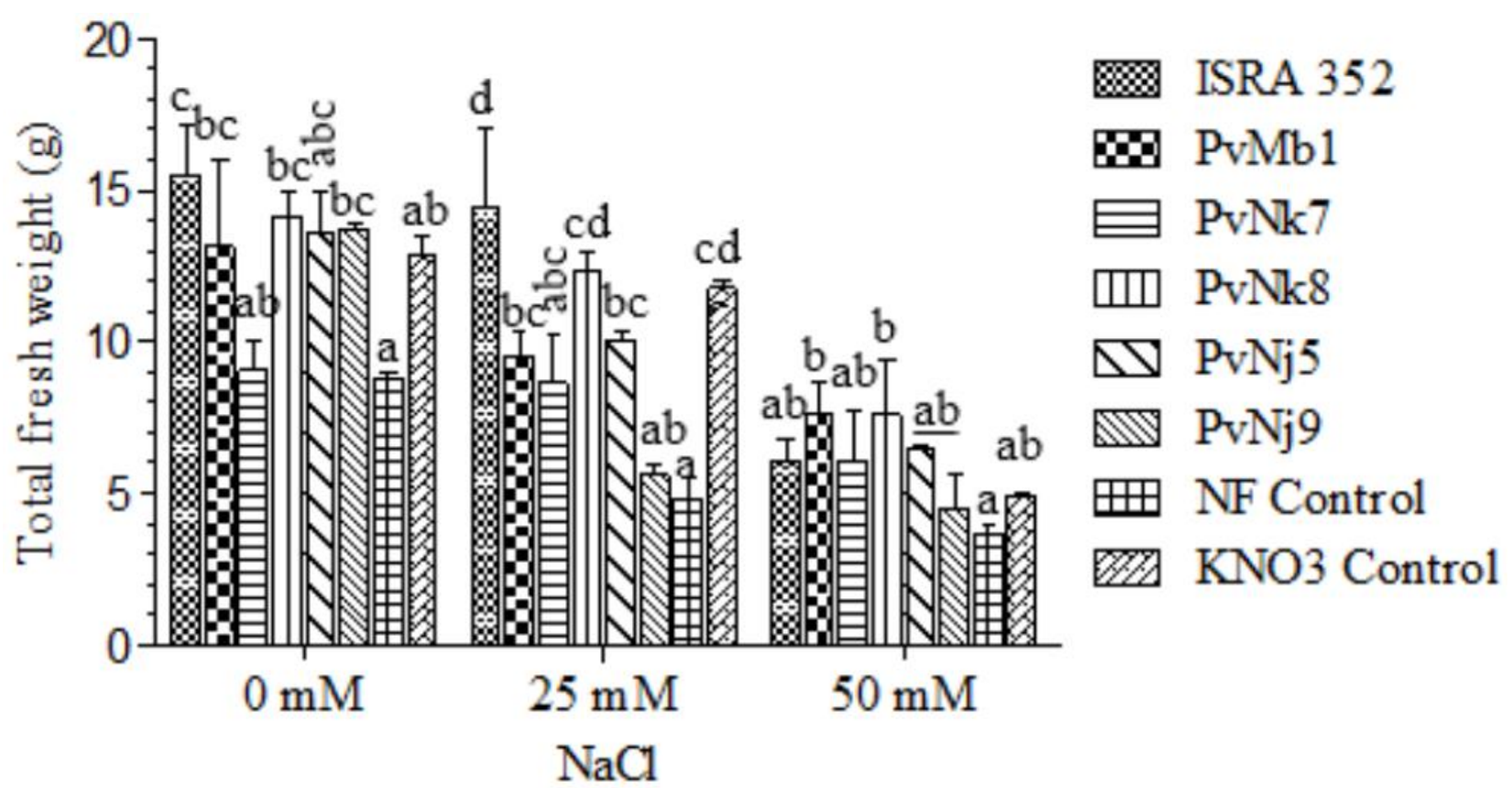

Figure 2. Effect of inoculation by rhizobia on common bean total fresh weight under salt stress. Note: Means with the same letters are not significantly different at $5 \%$ of average probability.

Total dry weight was also influenced by salinity Figure 3. The increase in $\mathrm{NaCl}$ concentration caused a decrease in the total dry weight of all the plants. Plant inoculation with ISRA 352, PvNk8 and PvNj9 gave results almost equivalent to those obtained by the positive control (KNO3 control).

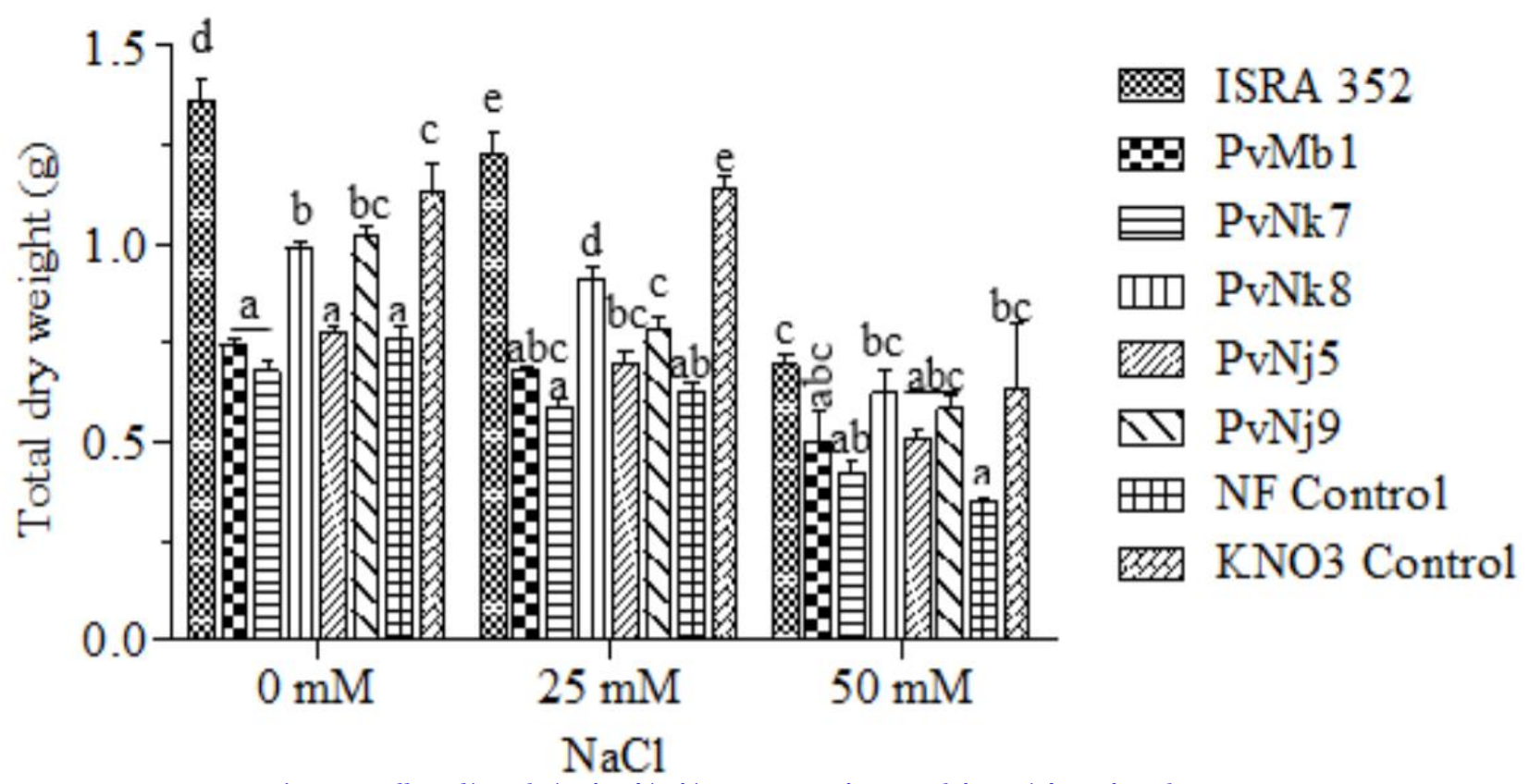

Figure 3. Effect of inoculation by rhizobia on common bean total dry weight under salt stress. Note: Means with the same letters are not significantly different at $5 \%$ of average probability.

Figure 4 shows that salt stress induces a reduction in plants water content. Control plant recorded the lowest values of water content (75.68\% and $74.94 \%$ respectively at $25 \mathrm{mM}$ and $50 \mathrm{mM}$ ). Plant inoculation by rhizobia as 
well as the application of $\mathrm{KNO}_{3}$ significantly improved water content at $50 \mathrm{mM} \mathrm{NaCl}$ compared to the negative control.

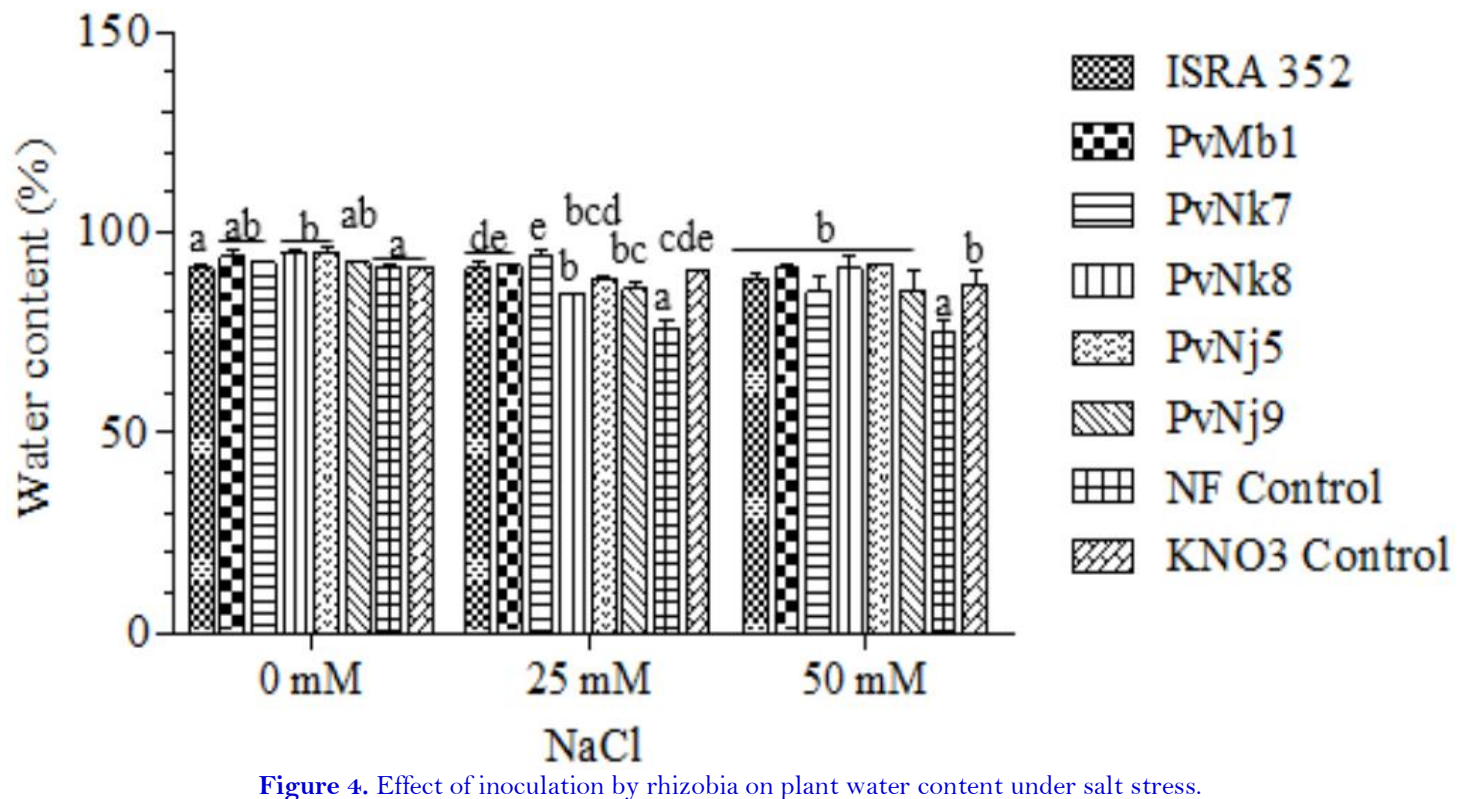

\subsection{Effect of Inoculation with Salt Tolerant Rhizobia on Symbiotic Parameters}

Figure 5 shows the number of nodules formed on bean roots under inoculation and salt constraint. Salinity has significantly reduced root nodules number. Plants inoculation with ISRA 352 provided significant highest number of nodules (34 nodules at o mM, 28 at $25 \mathrm{mM}$ and 24 nodules at $50 \mathrm{mM}$ ). No nodule was formed on the roots of the controls.

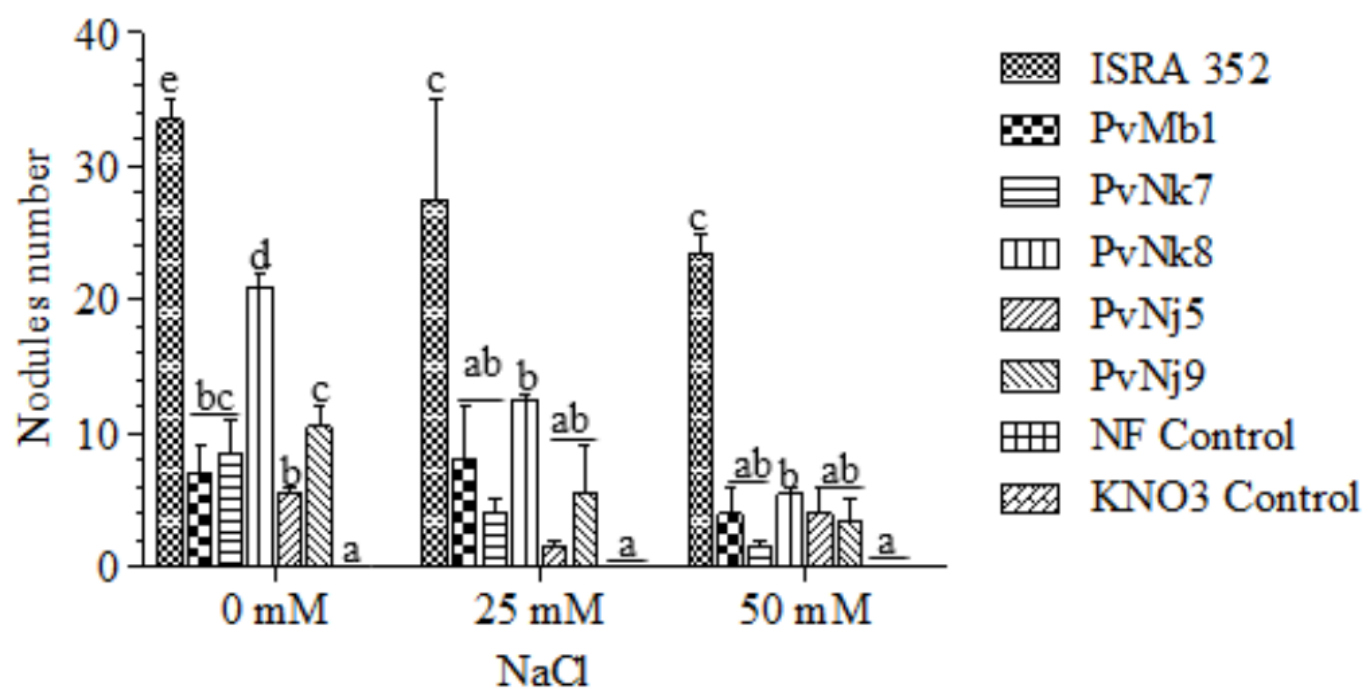

Figure 5. Effect of inoculation with rhizobia on the nodules number under salt stress.

The nodular index Figure 6 expressing the quality of symbiosis between the plant and the rhizobia isolates decreased with an increase in $\mathrm{NaCl}$ concentration. At $25 \mathrm{mM} \mathrm{NaCl}$, the nodular index was higher in ISRA 352 and PvNk7 isolates. Inoculation of the plants with ISRA 352 isolate achieved the highest nodular number even at 50 $\mathrm{mM}$. 


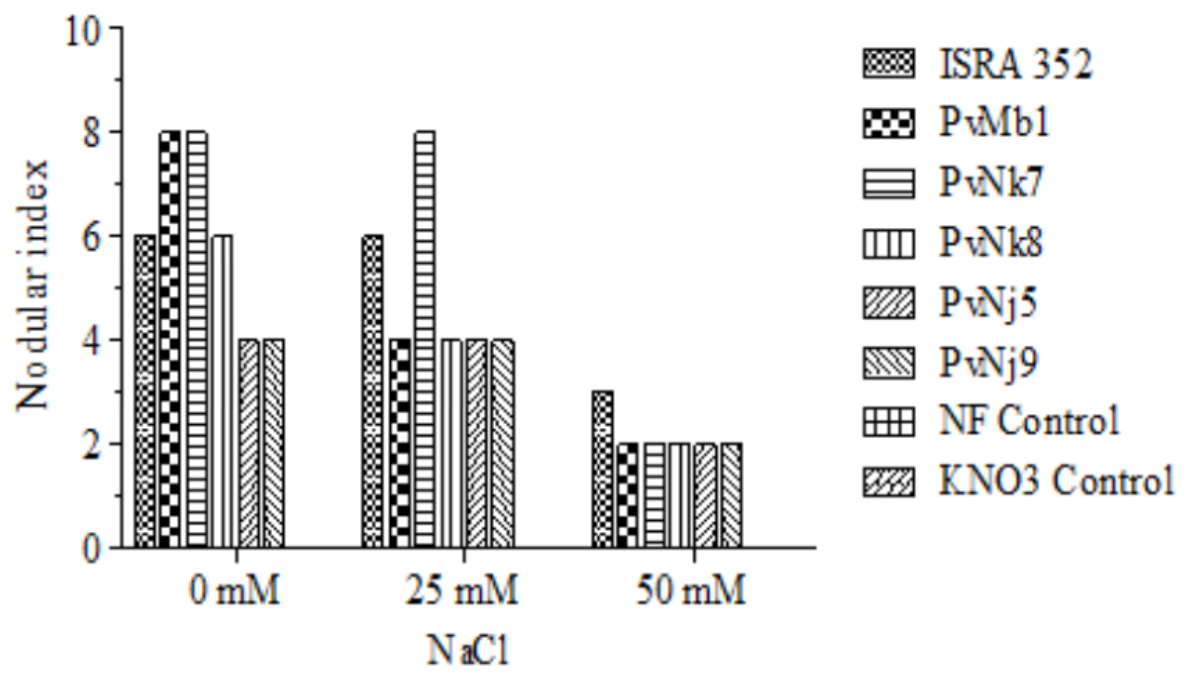

Figure 6. Nodular index evolution under salt condition.

\subsection{Effect of Inoculation on Total Chlorophyll and Carotenoids Contents}

Salt stress significantly reduced the total chlorophyll content of plants Figure 7. At all concentrations of $\mathrm{NaCl}$, the negative control recorded the lowest values $(38.54 \mathrm{mg} / \mathrm{L}, 39.54 \mathrm{mg} / \mathrm{L}$ and $32.20 \mathrm{mg} / \mathrm{L}$ ) significantly of chlorophyll at all concentrations of $\mathrm{NaCl}$ unlike the positive one in which the highest values are noted at $\mathrm{O} \mathrm{mM}(71$. $65 \mathrm{mg} / \mathrm{L})$ and $25 \mathrm{mM}(68.29 \mathrm{mg} / \mathrm{L})$. Inoculation with ISRA 352 and PvNk8 isolates resulted in better chlorophyll accumulation compared to other treatments at $50 \mathrm{mM}$.

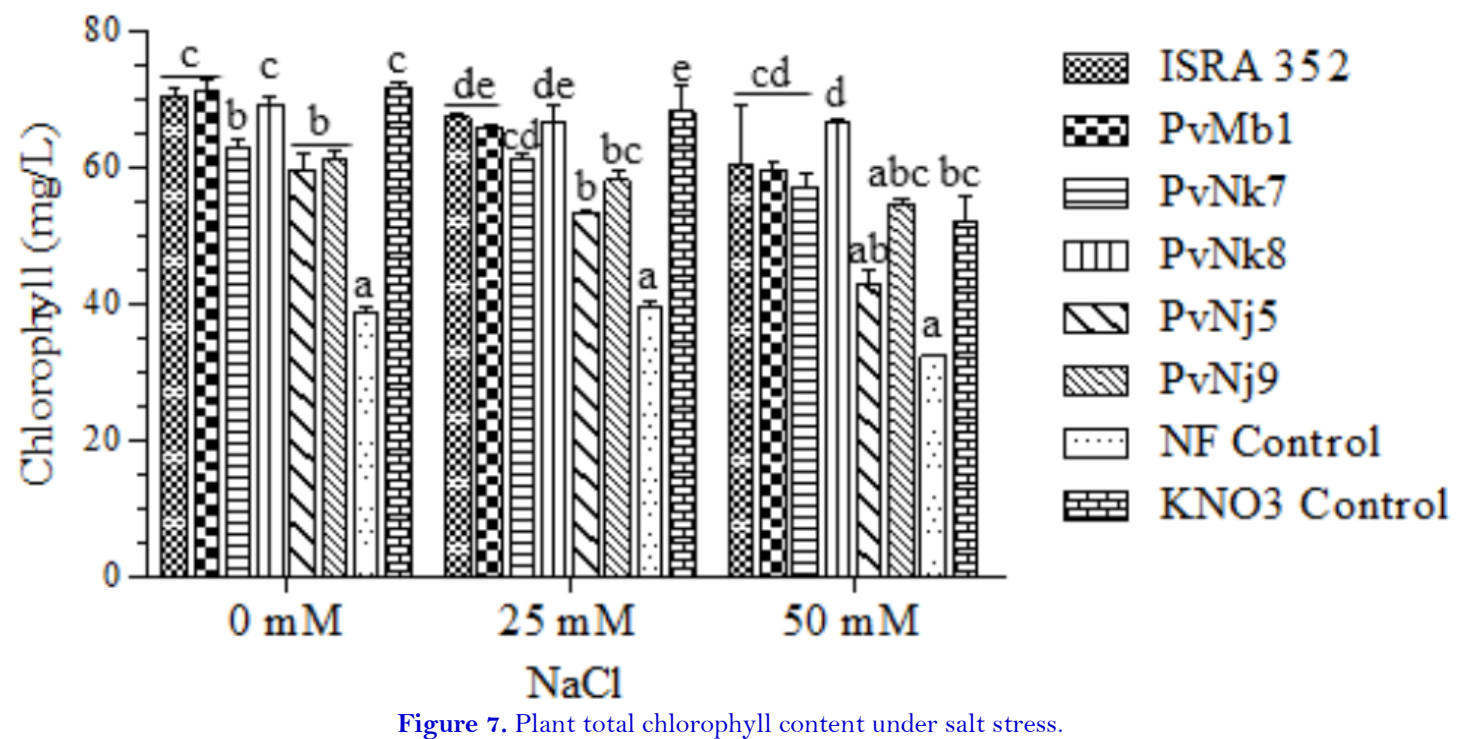

Figure 8 shows that there is an inversely proportional relationship between the carotenoid content of plants and the different doses of salt applied. Analysis of variance did not reveal any significant difference between the carotenoid levels by Duncan's test at concentrations of $\mathrm{o}$ and $25 \mathrm{mM}$. However, the highest levels were obtained in plants inoculated by ISRA352, PvNk8 and PvNk7 and the lowest in the negative control. At 50 mM two main homogeneous groups that are significantly different came out: The first group recording the highest values consists of ISRA $352(0.67 \mathrm{mg} / \mathrm{mL}), \operatorname{PvNj} 5(0.65 \mathrm{mg} / \mathrm{mL})$ and the positive control (0. $44 \mathrm{mg} / \mathrm{mL})$. The second group includes PvMb1 (0. $38 \mathrm{mg} / \mathrm{mL}$ ), PvNk7 (0. $25 \mathrm{mg} / \mathrm{mL})$, PvNk8 (0. $31 \mathrm{mg} / \mathrm{mL}), \operatorname{PvNj} 9$ (0. $27 \mathrm{mg} / \mathrm{mL})$ and the negative control (0.11 mg/mL). 


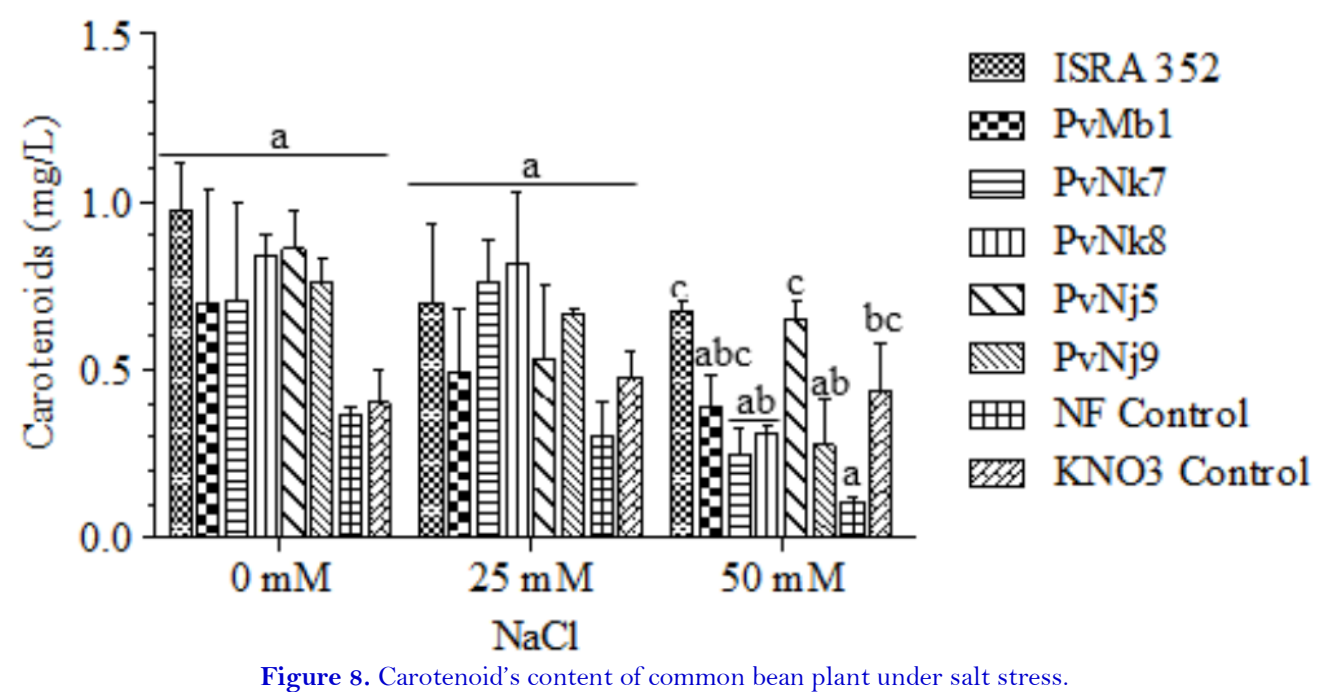

\subsection{Effect of Inoculation with Salt Tolerant Rhizobia on Physiological Stress Index}

The effect of salinity on plants resulted in a decrease in the physiological stress index Figure 9. The higher the stress index, the lower the stress is. At $0 \mathrm{mM} \mathrm{NaCl}$, the physiological stress index value of the plants did not show significant differences for all treatments. However, the lowest values were recorded in plants inoculated with PvNk7 as well as the negative control. At $25 \mathrm{mM} \mathrm{NaCl}$, plants inoculation by ISRA 352, PvMb1 and PvNk8 improves the physiological stress index respectively of 2. 10, 1. 90 and 1. 68. Inoculation did not significantly increase the physiological stress index at $50 \mathrm{mM} \mathrm{NaCl}$. Inoculated plants were found to be less sensitive to salt stress than non-inoculated ones.

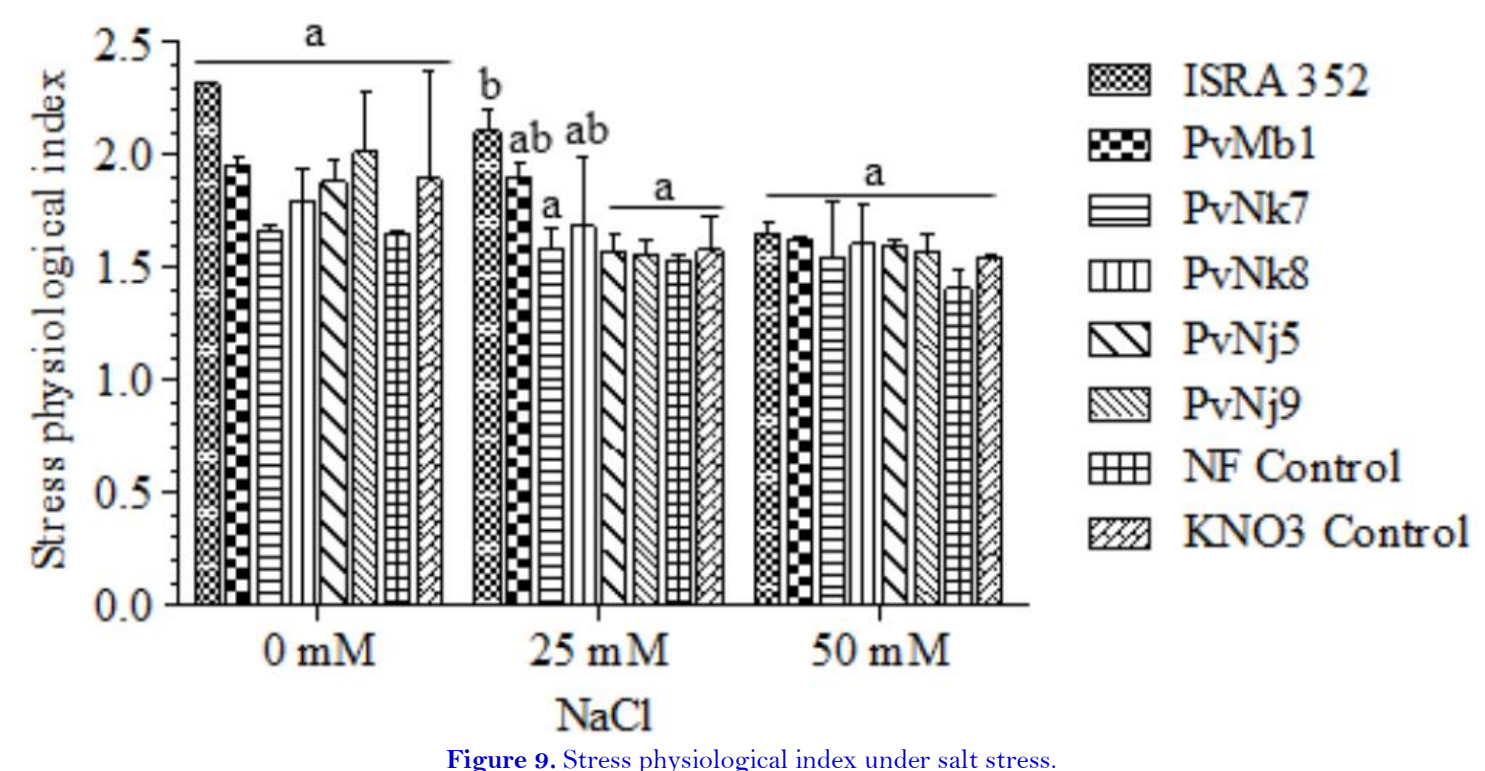

Table 1 shows that at the minimum concentration of $\mathrm{o} \mathrm{mM}$ of $\mathrm{NaCl}$, there is no stress for all inoculated plants as well as the $\mathrm{KNO}_{3}$ control with the exception of the negative control which exhibits low stress. At $25 \mathrm{mM}$ of $\mathrm{NaCl}$, only the plants inoculated by ISRA352, PvMb1 and PvNk8 did not exhibit stress. Inoculation with PvNk7, $\mathrm{PvNj}_{5}$ and $\mathrm{PvNj} 9$ in the presence of $25 \mathrm{mM} \mathrm{NaCl}$ caused intermediate stress. On the other hand, a proven stress was observed in negative control. At $50 \mathrm{mM}$, the stress was low for plants inoculated by ISRA352 and PvMb1 and intermediate for all other treatments. On the basis of those previous information, it appears that the isolates which most improved the tolerance to salt stress in bean plants are ISRA 352 and PvMb1. 
Table 1. Salinity effect on stress intensity in common bean plants.

\begin{tabular}{l|c|c|c}
\hline \multirow{2}{*}{ Isolates } & \multicolumn{3}{|c}{ Concentration of NaCl } \\
\cline { 2 - 4 } & $\mathbf{0 ~} \mathbf{~ M}$ & $\mathbf{2 5} \mathbf{~ m M}$ & $\mathbf{5 0} \mathbf{~ m M}$ \\
\hline ISRA 352 & No stress & No stress & Low stress \\
\hline PvMb1 1 & No stress & No stress & Low stress \\
\hline PvNk7 & No stress & Middle stress & Middle stress \\
\hline PvNk8 & No stress & No stress & Middle stress \\
\hline PvNj5 & No stress & Middle stress & Middle stress \\
\hline PvNj9 & No stress & Middle stress & Middle stress \\
\hline NF Control & Low stress & Stress & Stress \\
\hline KNO3 Control & No stress & Middle stress & Middle stress \\
\hline
\end{tabular}

\subsection{Effect of Inoculation by Salt Tolerant Rhizobia on Foliar Proline and Glycine Betaine Content}

Figure 10 shows the evolution of proline content in leaves under salt stress. Salt stress induced an increase in proline content in all plants. At $0 \mathrm{mM} \mathrm{NaCl}$, where salt stress is almost non-existent, the negative control shows the highest proline content with a value of $104.76 \mu \mathrm{g} / \mathrm{mL}$ significantly higher compared to the proline content accumulated in the positive control and in inoculated plants. This content was significantly different $(p<0.05)$ from all the other treatments which did not show any significant difference between them. At $25 \mathrm{mM}$, no significant difference was noted between treatments. However, inoculation with ISRA 352 and PvNk8 resulted in the highest proline levels of $130 \mu \mathrm{g} / \mathrm{mL}$ and 126. $66 \mu \mathrm{g} / \mathrm{mL}$, respectively. The highest proline contents were obtained when the $\mathrm{NaCl}$ concentration reached $50 \mathrm{mM}$. Plant inoculation with ISRA 352 resulted in a greater accumulation of proline of 183. $57 \mu \mathrm{g} / \mathrm{mL}$. At this concentration, the foliar proline content was significantly lower in plants inoculated $\mathrm{PvNj} 5$ and the negative control.

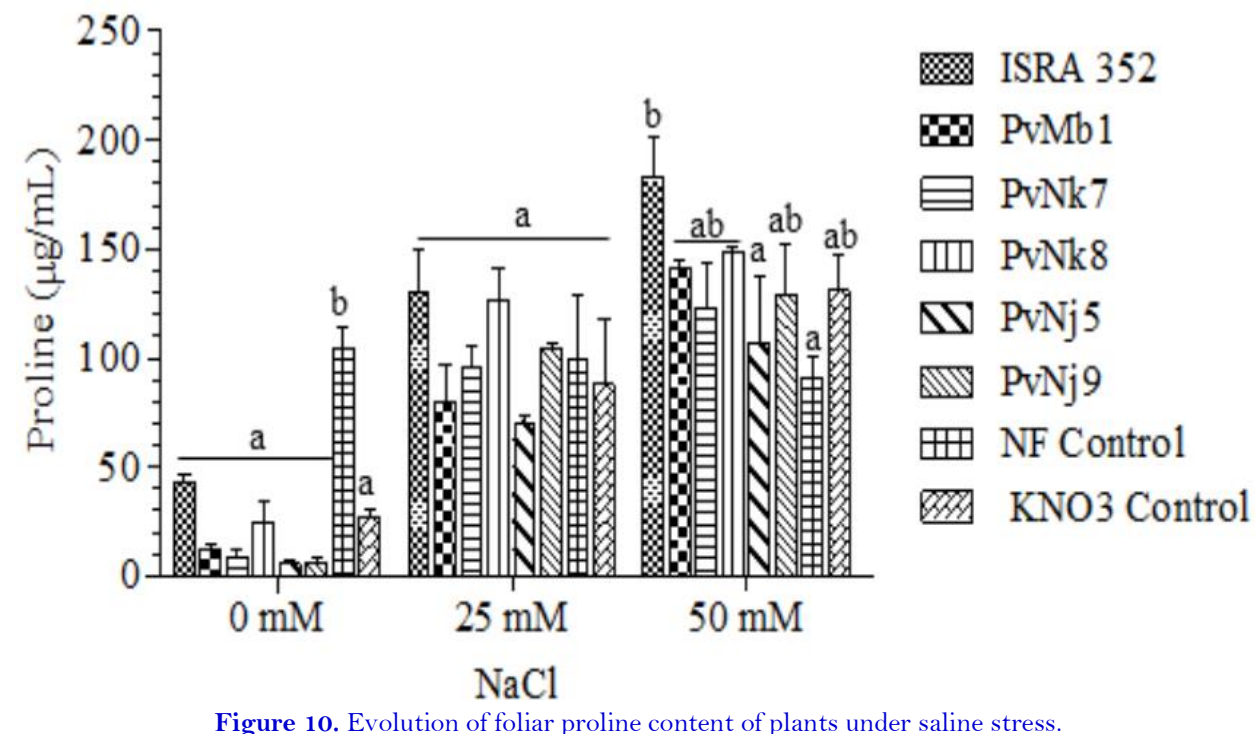

The increase in the salt concentration resulted in an increase in the amount of leaf glycine betaine in plants Figure 11. At o mM NaCl, the negative control exhibited the highest glycine betaine content $(97.11 \mu \mathrm{g} / \mathrm{mL})$ significantly higher than that of the positive control $(78.08 \mu \mathrm{g} / \mathrm{mL})$. At $25 \mathrm{mM} \mathrm{NaCl}$, no significant difference in the glycine betaine content was recorded in the leaves of plants inoculated with ISRA 352 compared to the proline content of bean plants inoculated with the other isolates. The highest levels of proline were obtained when the concentration of $\mathrm{NaCl}$ reached $50 \mathrm{mM}$. Plant inoculation increased glycine betaine levels but not significantly compared to controls. 


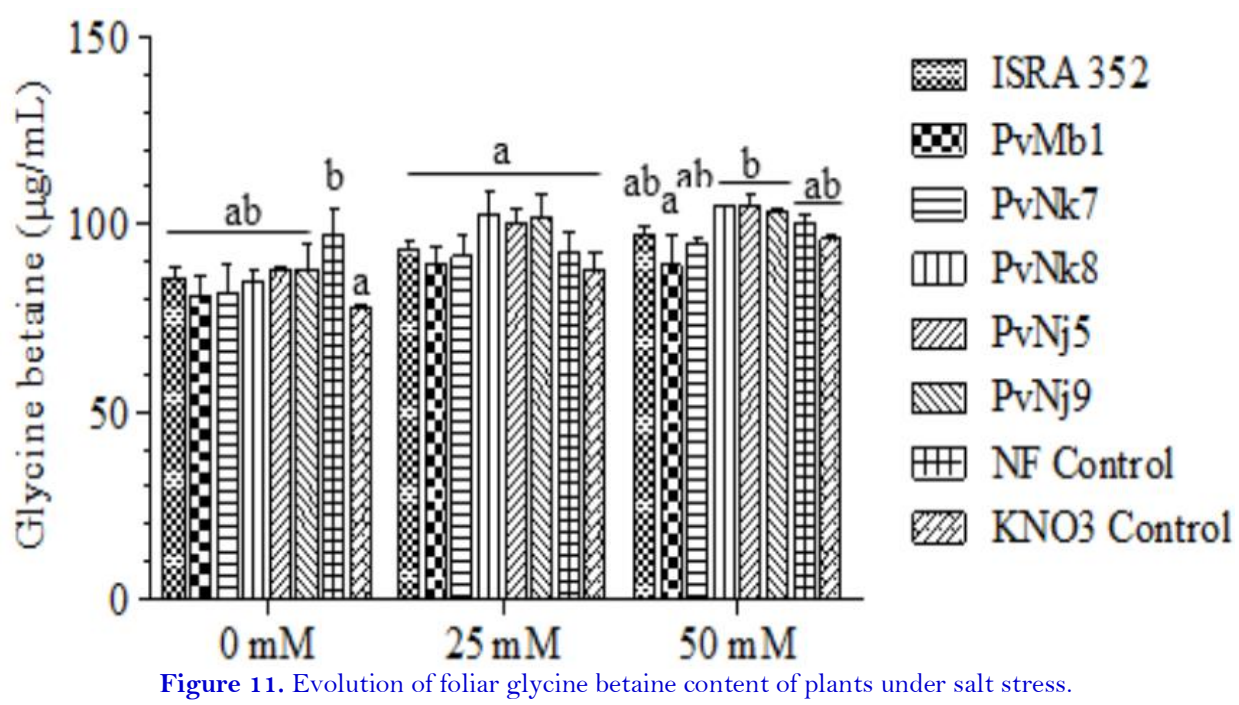

\section{DISCUSSION}

The study shows that salt stress has a negative effect on nodulation and total biomass of plants. These results confirmed those of Faghire, et al. [11] with mentioned the particular sensitivity of the common bean-rhizobia symbiosis to this environmental constraint. Saadallah, et al. [12] justify this reduction in weight growth by inhibiting the initiation and placement of nodules. This behavior is linked to a decrease in potential infection sites resulting essentially either from the reduction in the number and diameter of root hairs or even from the inhibition of the emergence and elongation of these organs Faghire, et al. [11].

Photosynthesis activity dropped under salt stress. These results corroborate with those obtained by El-Iklil, et al. [13] which reported a decrease in photosynthetic activity caused by a reduction in the conductance of the stomata, reducing transpiration and the entry of carbon dioxide [14]. The low levels of chlorophylls observed in the negative control could be the consequence of chlorosis caused by a nitrogen deficiency in the watering solution. Inoculation with nitrogen-fixing bacteria provides the plant with nitrogen in an assimilation form for chlorophyll synthesis and growth even under conditions of salt stress [15]. Analysis of the carotenoid contents of the common bean plants showed that, compared to the control plants, the carotenoids decreased significantly from $25 \mathrm{mM} \mathrm{NaCl}$. This reduction in levels is probably caused by the oxidative stress generated by the excessive salinity of the environment [13].

Salinity induces an accumulation of proline and glycine betaine in common bean leaves. The accumulation of these molecules was higher in inoculated plants, especially by ISRA352 and PvMb1 than in control plants. Plants and rhizobia accumulated compatible solutes as an adaptive mechanism to face the stress [16]. The accumulation of compatible solutes would allow an osmotic adjustment which will induce a decrease in the osmotic potential in order to allow an increase in water absorption and a reestablishment of the intracellular $\mathrm{NaCl}$ concentration $[17$, 18].

\section{CONCLUSION}

The study aimed to assess salt-tolerant rhizobia for their capacity to alleviate salt stress on common bean. In greenhouse, salinity significantly reduced plant nodulation and growth. However, plants inoculation with salttolerant rhizobia showed a significant increase in bean growth and tolerance compared to the negative control. Likewise, salt stress considerably reduced the amounts of total chlorophylls and carotenoids. Common bean inoculation increased pigments levels significantly compared to the control. The physiological stress index dropped considerably with salinity, indicating the degradation of chlorophyll. Salinity induced an accumulation of proline and glycine betaine in the leaves. The highest proline and betaine contents are recorded at $50 \mathrm{mM}$ in inoculated 
plants. This greenhouse inoculation work serve as a basis for the use of salt tolerant rhizobia adapted to saline environments in Cameroon or elsewhere. Regarding all the results, the major salt tolerant rhizobia able to alleviate salt stress in common bean are PvMb1, PvNk8 and PvNj5.

Funding: This study received no specific financial support.

Competing Interests: The authors declare that they have no competing interests.

Authors' Contributions: All authors contributed equally to the conception and design of the study.

Acknowledgement: Authors sincerely thank the LCM of Dakar-SENEGAL for the reference strain ISRA 352 provided.

\section{REFERENCES}

[1] R. Munns and M. Tester, "Mechanisms of salinity tolerance," Annual Revue Plant Physiology, vol. 59, pp. 651-681, 2008.

[2] R. Munns, "Genes and salt tolerance: Bringing them together," New Phytologist, vol. 167, pp. 645-663, 2005.Available at: https://doi.org/10.1111/j.1469-8137.2005.01487.x.

[3] N. A. Milosevic, J. B. Marinković, and B. B. Tintor, "Mitigating abiotic stress in crop plants by microorganisms," Proceedings of the Matica Srpska for Natural Sciences, vol. 123, pp. 17-26, 2012.

[4] D. Egamberdieva, S. Wirth, S. D. Bellingrath-Kimura, J. Mishra, and N. K. Arora, "Salt-tolerant plant growth promoting rhizobacteria for enhancing crop productivity of saline soils," Frontiers in Microbiology, vol. 10, pp. 27912791, 2019.Available at: https://doi.org/10.3389/fmicb.2019.02791.

[5] G. H. S. Youagang, N. L. Ngo, C. C. Asseng, N. A. I. C. Nyaka, A. Ngakou, and D. Nwaga, "Isolation and characterization of Legume Nodulating Bacteria Isolated from common bean (Phaseolus vulgaris L.) nodules," Global Scientific Journals, vol. 8, pp. 1777-1792, 2020.

[6] H. K. Lichtenthaler, "Chlorophylls and carotenoids: Pigments of photosynthetic biomembranes," Methods in Enzymology, vol. 148, pp. 350-382, 1987.Available at: https://doi.org/10.1016/0076-6879(87)48036-1.

[7] J.-K. Zhu, "Regulation of ion homeostasis under salt stress," Current Opinion in Plant Biology, vol. 6, pp. 441-445, 2003.Available at: https://doi.org/10.1016/s1369-5266(03)00085-2.

[8] J. Lopez and A. Carballeira, "A comparative study of pigment contents and response to stress in five species of aquatic bryophytes," Lindbergia, vol. 15, pp. 188-194, 1989.

[9] W. Troll and J. Lindsley, "A photometric method for the determination of proline," Journal of Biological Chemistry, vol. 215 , pp. 655-660, 1955.

[10] C. Grieve and S. Grattan, "Rapid assay for determination of water soluble quaternary ammonium compounds," Plant and Soil, vol. 70, pp. 303-307, 1983.Available at: https://doi.org/10.1007/BFo2374789.

[11] M. Faghire, B. Mandri, K. Oufdou, A. Bargaz, C. Ghoulam, M. H. Ramírez-Bahena, E. Velázquez, and A. Peix, "Identification at the species and symbiovar levels of strains nodulating Phaseolus vulgaris in saline soils of the Marrakech region (Morocco) and analysis of the otsA gene putatively involved in osmotolerance," Systematic and Applied Microbiology, vol. 35, pp. 156-164, 2012.Available at: https://doi.org/10.1016/j.syapm.2012.02.003.

[12] K. Saadallah, J.-J. Drevon, and C. Abdelly, "Nodulation et croissance nodulaire chez le haricot (Phaseolus vulgaris) sous contrainte saline," Agronomie, vol. 21, pp. 627-634, 2001.Available at: https://doi.org/10.1051/agro:2001154.

[13] Y. El-Iklil, M. Karrou, R. Mrabet, and M. Benichou, "Effect of salt stress on the variation of certain metabolites in Lycopersicon esculentum and Lycopersicon sheesmanii," Canadian Journal of Plant Science, vol. 82, pp. 177-183, 2002.Available at: https://doi.org/10.4141//po0-175.

[14] C. Nunes, S. Araújo, J. Silva, P. Fevereiro, and A. Silva, "Photosynthesis light curves: A method for screening water deficit resistance in the model legume Medicago truncatula," Annals of Applied Biology, vol. 155, pp. 321-332, 2009.Available at: https://doi.org/10.1111/j.1744-7348.2009.00341.x.

[15] A.-L. He, S.-Q. Niu, Q. Zhao, Y.-S. Li, J.-Y. Gou, H.-J. Gao, S.-Z. Suo, and J.-L. Zhang, "Induced salt tolerance of perennial ryegrass by a novel bacterium strain from the rhizosphere of a desert shrub Haloxylon ammodendron," International Journal of Molecular Sciences, vol. 19, pp. 1-19, 2018.Available at: https://doi.org/10.3390/ijms 19020469. 
[16] M. Ngom, R. Oshone, N. Diagne, M. Cissoko, S. Svistoonoff, L. S. Tisa, L. Laplaze, M. O. Sy, and A. Champion, "Tolerance to environmental stress by the nitrogen-fixing actinobacterium Frankia and its role in actinorhizal plants adaptation," Symbiosis, vol. 70, pp. 17-29, 2016.Available at: https://doi.org/10.1007/s13199-016-0396-9.

[17] T. Chen and N. Murata, "Enhancement of tolerance of abiotic stress by metabolic engineering of betaines and other compatible solutes," Current Opinion in Plant Biology, vol. 5, pp. 250-257, 2002.Available at: https://doi.org/10.1016/s1369-5266(02)00255-8.

[18] V. Sandhya, S. Z. Ali, M. Grover, G. Reddy, and B. Venkateswarlu, "Effect of plant growth promoting Pseudomonas spp. on compatible solutes, antioxidant status and plant growth of maize under drought stress," Plant Growth Regulation, vol. 62, pp. 21-30, 2010.Available at: https://doi.org/10.1007/s10725-010-9479-4. 